\title{
Surface modification of molten W exposed to high heat flux helium neutral beams
}

\author{
Y. Yuan ${ }^{1}$, H. Greuner ${ }^{2}$, B. Böswirth², Ch. Linsmeier ${ }^{2}$, G.-N. Luo ${ }^{3}$, B.Q. Fu ${ }^{1}$, H.Y. Xu ${ }^{1}$, Z.J. \\ Shen $^{1,4}$, W. Liu ${ }^{1, *}$ \\ ${ }^{1}$ Department of Material Science and Engineering, Tsinghua University, Beijing 100084, China \\ ${ }^{2}$ Max-Planck-Institute for Plasma Physics, EURATOM Association, Boltzmannstr. 2, 85748 Garching, \\ Germany \\ ${ }^{3}$ Institute of Plasma Physics, Chinese Academy of Sciences, Hefei, Anhui 230031, China \\ ${ }^{4}$ Department of Materials and Environmental Chemistry, Arrhenius Laboratory, Stockholm University, \\ S-106 91 Stockholm, Sweden
}

\begin{abstract}
High heat flux tests with central heat flux of $10.5 \mathrm{MW} / \mathrm{m}^{2}$ using helium neutral beams have been carried out on rolled tungsten. The energy of helium particles is 33 $\mathrm{keV}$ and the particle flux is $2 \times 10^{21} \mathrm{~m}^{-2} \mathrm{~s}^{-1}$. An $80 \times 65 \times 3 \mathrm{~mm}^{3}$ rolled tungsten plate is firstly exposed to a $4.6 \mathrm{~s}$ pulse resulting in partially molten surfaces. Thereafter the tungsten plate is irradiated by several helium pulses with fluences of $1.2-2.5 \times 10^{22} / \mathrm{m}^{2}$ and peak temperatures from 1450 to $2590{ }^{\circ} \mathrm{C}$. The experiments show that: (1) helium-induced surface modification of the resolidified tungsten surface is very different from that of the non-molten surface; (2) the surface morphology of molten surface is closely related to the orientation of the resolidified grain; (3) the evolution of surface modifications, for both of the molten and non-molten tungsten surfaces,

* Corresponding author. Tel.: +86 10 62772852; fax: +861062771160

E-mail address: liuw@mail.tsinghua.edu.cn
\end{abstract}


indicates a strong dependence on the surface temperature and local helium fluence.

Key words: surface modification; tungsten; melting; high heat flux; helium

\section{Introduction}

Tungsten $(\mathrm{W})$ is chosen as a plasma facing material (PFM) in many future fusion devices because of its high melting point and low erosion yield. Tungsten will be exposed to extreme conditions during operations, i.e. particle irradiation (helium and hydrogen isotopes) and high heat flux (HHF) loads. Particle irradiation, especially helium irradiation, has been considered to be a serious concern to the performance of metallic PFMs [1]. Helium bombardment leads to helium bubbles and holes which cause the degradation of material properties and also strongly influence the retention of hydrogen isotopes [2,3].

HHF loads may lead to surface melting of $\mathrm{W}$ materials which further results in large material erosion and dramatic changes of microstructures and properties of the resolidified material [4,5]. The material damaged after melting will also experience simultaneous heat and particle loads in subsequent operations. However, few studies are available on the synergistic effects of HHF loading and helium implantation on molten and resolidified tungsten.

In this study, high heat flux experiments performed with a helium neutral beam have been carried out in the high heat flux test facility GLADIS (Garching LArge DIvertor Sample test facility) at IPP Garching [6,7], aiming at the investigation of the 
combined effects of high heat loading and helium irradiation on molten and resolidified tungsten. For comparison, surface modification of non-molten tungsten under identical irradiation conditions is also studied.

\section{Experimental}

Material used in the present work is high purity (>99.9\%) rolled tungsten. It is produced by powder sintering followed by warm rolling $\left(\sim 1200{ }^{\circ} \mathrm{C}\right)$ to $75 \%$ reduction in thickness (final thickness $\sim 3 \mathrm{~mm}$ ) which results in an average grain size of $<5 \mu \mathrm{m}$. The test samples are cut to $80 \times 65 \times 3 \mathrm{~mm}^{3}$ pieces by wire-electro discharge.

Two pieces of W samples (W1 and W2) are mounted on carbon fiber reinforced composite (CFC) sample holders (Fig. 1(a)). The sample installation and the design of cooling structure are consistent with our pervious study [8]. The sample surface is perpendicular to the beam axis. Pulsed helium beams with central heat flux of 10.5 $\mathrm{MW} / \mathrm{m}^{2}$ are applied (Fig. 2). The $33 \mathrm{keV}$ helium atoms result in a central helium flux of $2 \times 10^{21} \mathrm{~m}^{-2} \mathrm{~s}^{-1}$ [9]. Since the particle flux variation is the reason for the local heat flux variation in our experiments, the particle flux profile is extrapolated according to the measured heat flux distribution shown in Fig. 2. To simplify the particle flux profile, we assume a constant flux $2 \times 10^{21} \mathrm{~m}^{-2} \mathrm{~s}^{-1}$ for the beam centre (radius $r \leq 30 \mathrm{~mm}$ ). For $r>30 \mathrm{~mm}$, we set the particle flux profile proportional to the heat flux one.

The HHF tests consist of two steps. Step I: the beam centre is located at position P1, i.e. the centre of W1 (Fig. 1(a)). In this case, W1 is loaded with power densities in the range of $9-10.5 \mathrm{MW} / \mathrm{m}^{2}$ as shown in the central hatched area in Fig. 2. A pulse 
with duration of $4.6 \mathrm{~s}$ is applied and results in a big molten area as shown in Fig. 1(b). Step II: the beam centre moves to P2, the centre of W2. In this case, W1 is loaded with lower power densities, in the range of $2.5-8 \mathrm{MW} / \mathrm{m}^{2}$, as shown in the left hatched area in Fig. 2. Five pulses with duration of 3.5, 3.7, 3.9, 4.1 and $4.3 \mathrm{~s}$, respectively, are performed in sequence. The interval between consecutive pulses is 6-8 minutes so as to ensure that the loaded samples are cooled down to room temperature.

The surface temperature was recorded by a one-color $\left(650-2200^{\circ} \mathrm{C}\right)$, a two-color pyrometer $\left(550-1700{ }^{\circ} \mathrm{C}\right.$ ) and an IR camera (10 frames/s, $10 \mu \mathrm{m}$ wave length), respectively. Extrapolation of temperatures beyond the pyrometer measurement ranges was performed by the post-processing of IR thermograms according to the reference [8]. Since the surface emissivity changed due to the surface modification induced by helium irradiation [10], the IR thermograms were replaced by the ones recorded during hydrogen operation with the same heat loading conditions. In addition, the emissivity would be different for the resolidified layer of W1. We adopted a similar approach when we measured the temperature distribution on the resolidified layer during the subsequent loading in step II, namely, using the IR thermograms of a non-molten sample under the identical hydrogen HHF loads.

Four positions on the non-molten area (N1-N4) and three positions on the molten area (M1-M3) of sample W1 were picked for investigating the surface modifications, as shown in Fig. 1(b). The main parameters including local helium fluences and local peak temperatures for these positions during the two loading steps are listed in Table 
1. Surface morphologies both before and after helium loading tests were observed with a scanning electron microscope (SEM). Orientations of the resolidified grains were examined by electron backscattered diffraction (EBSD) analysis. Subsurface damages after helium irradiation were analyzed by focused ion beam (FIB) technology.

\section{Results and discussion}

\subsection{Surface morphology changes after step I}

In step I, the W plate was exposed to power densities of $9-10.5 \mathrm{MW} / \mathrm{m}^{2}$ for $4.6 \mathrm{~s}$. The thin $\mathrm{W}$ plate bent and cracked on the upper part due to the thermal expansion under the HHF load (Fig. 1(b)). However, this did not affect the helium irradiation tests in step II and the observations of surface modification.

The original rough surface after grinding is shown in Fig. 3(a). After step I, a big molten area with $\sim 40 \mathrm{~mm}$ in diameter was formed in the sample centre (Fig. 1(b)). The surface morphology of the molten area is shown in Fig. 3(b): big grains with locally smooth surface and without obvious evidence of helium-induced modification.

The circumjacent non-molten positions N1-N4 were irradiated by $33 \mathrm{keV}$ helium atoms with fluence of $9.2 \times 10^{21} / \mathrm{m}^{2}$ at peak temperatures below the melting point. The peak surface temperatures of $\mathrm{N} 1-\mathrm{N} 4$ ranged from $\sim 3100{ }^{\circ} \mathrm{C}$ to up to $3410{ }^{\circ} \mathrm{C}$. Due to similar peak surface temperatures, the surface morphologies were similar at these four positions. A typical irradiated surface morphology at N2 after step I is shown in Fig. 3(c). Holes with an average diameter of $\sim 0.5 \mu \mathrm{m}$ were observed. Similar porous 
surface morphologies were found on $\mathrm{W}$ samples after helium irradiations in other investigations, e.g. [9-13]. A FIB cross-section of the porous surface at N2 is shown in Fig. 3(d). A lot of submicron pores/bubbles $(\sim 0.2 \mu \mathrm{m})$ disperse at a depth of up to 1 $\mu \mathrm{m}$. Some small pores/bubbles are found near the bottom of the big hole. The holes visible on the surface are believed to be correlated to the helium bubble formation in the near surface and the porous surface structure is supposed to be formed by the helium bubbles bisecting the surface when they meet the top surface [9-13].

The energy of incident helium particles $(33 \mathrm{keV})$ in this work was much larger than the sputtering threshold for helium on $\mathrm{W}(\sim 100 \mathrm{eV} \mathrm{[13]).} \mathrm{With} \mathrm{fluence} \mathrm{of}$ $9.2 \times 10^{21} / \mathrm{m}^{2}$ (step I), it can only lead to about $0.005 \mu \mathrm{m}$ physical sputtering erosion according to the calculation results [13], which is negligible compared to the scale of holes $(0.1 \mu \mathrm{m})$ on the irradiated surface (Fig. 3(c)). When the helium fluence increases to $1.2-2.5 \times 10^{22} / \mathrm{m}^{2}$ (step II), the resulting sputtering erosion is $0.008-0.015$ $\mu \mathrm{m}$ [13]. It would also slightly affect the evolution of the surface morphology (Fig. 4-6). Therefore, we do not discuss the physical sputtering further here.

\subsection{Surface modifications of the molten and non-molten tungsten under repeated high} heat flux helium beam loading in step II

In step II, the damaged W sample with molten and non-molten (initially irradiated) areas was exposed to power densities in a lower range and with a significant variation, i.e. from 2.5 to $8 \mathrm{MW} / \mathrm{m}^{2}$. The local particle flux also had simultaneous changes. We linearly extrapolated the local particle fluxes for the seven investigated positions 
according to the decreases of local heat fluxes (Fig. 2). The accumulated helium fluences during the five pulses, i.e. $3.5,3.7,3.9,4.1$ and $4.3 \mathrm{~s}$, for different positions are listed in Table 1. The start temperature for each pulse was the same, i.e. ambient temperature. Hence, the maximum temperature during these five pulses was the peak temperature obtained at the end of $4.3 \mathrm{~s}$ loading (the longest pulse). In this paper, the temperatures corresponding to step II refer to the peak surface temperatures at $4.3 \mathrm{~s}$.

\subsubsection{Surface modification of the non-molten tungsten after helium irradiation in step}

II

Fig. 4 shows the surface modifications of the four non-molten positions (N1-N4) irradiated by repeated helium pulses with fluences of $1.2-2.5 \times 10^{22} / \mathrm{m}^{2}$ at various peak temperatures of $1450-2590{ }^{\circ} \mathrm{C}$. Position N1 with a peak temperature of $1450{ }^{\circ} \mathrm{C}$ (Fig. 4(a)) and a helium fluence of $1.2 \times 10^{22} / \mathrm{m}^{2}$ shows little change compared to the initially irradiated one before the subsequent irradiation process (Fig. 3(c)), i.e. a porous surface with big holes $(\sim 0.5 \mu \mathrm{m})$. When the peak temperature and helium fluence approach $1800{ }^{\circ} \mathrm{C}$ and $1.6 \times 10^{22} / \mathrm{m}^{2}$, the original big holes still survive after the loading, and meanwhile, densely distributed pinholes are formed on the bottom as well as inter areas of big holes (Fig. 4(b), N2). The corresponding detailed subsurface structure is shown in Fig. 4(c). Small pores with a diameter of $\sim 0.2 \mu \mathrm{m}$ locating in the near surface (up to $1 \mu \mathrm{m}$ ) are similar to those shown in Fig. 3(d) after step I. Besides, lots of fine pores $(\sim 0.05 \mu \mathrm{m})$ are observed in the shallow surface $(\sim 0.3 \mu \mathrm{m})$. These observations indicate that the subsequent irradiation at $1800{ }^{\circ} \mathrm{C}$ and $1.6 \times 10^{22} \mathrm{He} / \mathrm{m}^{2}$ 
leads to the formation of the fine bubbles in the shallow surface with depth of $\sim 0.3$ $\mu \mathrm{m}$, and some of the fine bubbles bisect the surface resulting in the pinholes as shown in Fig. 4(b). The pinholes grow bigger at $2340{ }^{\circ} \mathrm{C}, 2.2 \times 10^{22} \mathrm{He} / \mathrm{m}^{2}$ (N3, Fig. 4(d)). As a result, they blur the boundaries of the original big holes and constitute a new porous surface morphology. When the peak temperature and local helium fluence further rise to $2590{ }^{\circ} \mathrm{C}$ and $2.5 \times 10^{22} / \mathrm{m}^{2}$ (N4, Fig. 4(e)), the original big holes can be hardly distinguished and the surface morphology develops to a coral-like structure. From the FIB cross-section at N4 (Fig. 4(f)), the protuberances with pores inside can be clearly observed. Comparing Fig. 4(c) and (f), we can figure out the evolution of the surface structure as: with increasing peak temperature and local helium fluence, the thermal migration of helium bubbles and coalescence of holes and the adjacent bubbles get more intense [2]; the coalescence of holes and the helium bubbles near their bottoms results in the growth of holes in depth [14], which finally leads to the formation of the protuberances as shown in Fig. 4(f). The depth of surface damage induced by the repeated helium irradiation in step II increases from $\sim 0.3 \mu \mathrm{m}$ (Fig. $4(\mathrm{c})$ ) at $1800{ }^{\circ} \mathrm{C}$ and $1.6 \times 10^{22} \mathrm{He} / \mathrm{m}^{2}$ to $\sim 1.2 \mu \mathrm{m}$ (Fig. 4(f)) at $2590{ }^{\circ} \mathrm{C}$ and $2.5 \times 10^{22} \mathrm{He} / \mathrm{m}^{2}$. Although the surface damage induced by the pre-irradiation in step I could affect the structure evolutions of the non-molten W during step II, the strong dependence of the helium-induced surface modifications on the surface temperature and local helium fluence is obvious.

\subsubsection{Surface modification of the molten tungsten after helium irradiation in step II}


For the leftmost position of the molten area, M1, with the lowest peak temperature and helium fluence over the whole molten layer, $1730{ }^{\circ} \mathrm{C}$ and $1.4 \times 10^{22}$ $/ \mathrm{m}^{2}$, lots of blisters can be found on the initially smooth resolidified grain surface (Fig. 5(a) and (b)). The density and morphology of the features visible in Fig. 5(a) and (b) is significantly different on different grains. On grains A and B, similar features, which appear little blisters, are visible. Their density is smaller on grain A than on grain B. Blister-like structures without caps are observed on grain C. About 30 resolidified grains with similar surface features on grain $\mathrm{A}, \mathrm{B}$ and $\mathrm{C}$ were picked. Their crystallographic orientations were investigated by EBSD and the surface orientations (normal direction (ND)) are shown as inverse pole figure in Fig. 5(c). Orientations of these grains are classified according to the degree of blistering which are indicated by different symbols: black dots "light" (as grain A), blue square "medium" (as grain B) and red triangle "heavy" (as grain C). It is evident that blistering slightly occurs on the resolidified grains with surface orientation near (001), and it gets heavier on the grains near (011), and the grains near (111) suffer the greatest damage. W grains near (111) surface orientation have been also found to be most prone to blistering when exposed to high flux deuterium plasmas $[3,15]$. A FIB cut on grain $\mathrm{C}$ was performed through two neighboring broken blisters which are marked by the short red line in Fig. 5(b). The cross-sectional view is shown in Fig. 5(d). Lots of pinholes are clearly observed on the top surface and the bottom of the open blisters. Meanwhile, the intact resolidified bulk can be observed which implies that there is little pre-irradiation effect after helium bombardment in step I. The 
thickness of the damaged surface is $\sim 0.2 \mu \mathrm{m}$ including the blister skin of $\sim 0.1 \mu \mathrm{m}$. It is smaller than that for the non-molten area $(\mathrm{N} 2, \sim 0.3 \mu \mathrm{m})$ under similar irradiation conditions $\left(1800{ }^{\circ} \mathrm{C}, 1.6 \times 10^{22} \mathrm{He} / \mathrm{m}^{2}\right)$.

At M2 $\left(1950{ }^{\circ} \mathrm{C}, 1.8 \times 10^{22} / \mathrm{m}^{2}\right)$, raised spherical blisters and dense pinholes can be seen. The degree of blistering is different between grain D and E (Fig. 6(a)) which also exhibits the dependence of surface modification on the grain orientation.

When the peak temperature and local helium fluence increase to $2460{ }^{\circ} \mathrm{C}$ and $2.3 \times 10^{22} / \mathrm{m}^{2}$ (M3), no blisters can be observed (Fig. 6(b)) which is very different from M1 and M2. However, the surface morphology dependence on the grain orientation can still be observed, i.e. porous structure on grain $\mathrm{F}$ and coral-like structure on grain G. Since the top surface has been severely destroyed after helium irradiation, the original surface orientations of grain $\mathrm{F}$ and $\mathrm{G}$ are difficult to be analyzed by EBSD. Results of FIB cross-section analysis on grain F and G are shown in Fig.6 (c) and (d), respectively. For grain F, many small pores can be found on the inner wall of the holes, and some small cavities fill the big hole. For grain G, the surface seems to suffer much more serious damage compared with grain F. Protuberances with pores are left on the irradiated grain surface similar as the surface features at N4 (Fig.4(f)). The protuberances would also be ascribed to the digging mechanism as we have discussed in Section 3.2.1. The surface structures are still different for different resolidified grains at even harsher irradiation conditions at M3. However, one common thing here is that the blisters as we see at M1 and M2 do not appear any longer. The average depth of surface damage is up to $0.9 \mu \mathrm{m}$ at M3. It significantly rises compared with 
M1 $(\sim 0.2 \mu \mathrm{m})$ which is subjected to lower temperature and helium fluence. However, the depth of damaged surface at M3 is smaller than that of non-molten area (N4, 1.2 $\mu \mathrm{m})$ which experiences analogous irradiation. The above observations about helium-induced surface modifications on the resolidified W surface indicate that: 1) blisters are formed on the smooth resolidified grain surface, and their density and morphology (intact or ruptured) is highly related to the grain orientation; 2) blisters disappear when the peak temperature and helium fluence rise to $2460{ }^{\circ} \mathrm{C}$ and $2.3 \times 10^{22}$ $/ \mathrm{m}^{2}$. However, the surface morphologies still vary with different grains; 3) the depth of surface damage significantly increases with increasing peak temperature and local helium fluence.

\subsubsection{Comparison of surface modifications on molten and non-molten tungsten} surface exposed to high heat flux helium neutral beams

A peculiar phenomenon for the molten $\mathrm{W}$ surface is the structure of blisters, and the blistering degree is found to be orientation dependent. The relationship between the blistering degree and the grain orientation is representatively studied at M1 $\left(1730{ }^{\circ} \mathrm{C}, 1.4 \times 10^{22} \mathrm{He} / \mathrm{m}^{2}\right)$, which indicates that the surfaces with orientations near (001) are least blistering and (011) orientation follows, and (111) orientation suffers the most serious damage, i.e. blister bursting (Fig. 5). Blister formation on helium-irradiated metal surfaces can be explained by the interbubble fracture model which claims that the coalescence of overpressurised bubbles in the subsurface region causes crack formation, and the pressure in the crack increases due to the increasing 
number of bubbles adjacent to the original crack getting involved, which drives the top surface deformation resulting in the formation of blisters $[16,17]$. (111) has the lowest atoms density in the three involved planes, (111), (011) and (001). Therefore, the blister lid on W (111) surface is most likely to rupture during blister swelling due to the weakest interaction between the atoms. Moreover, the helium blisters cannot be observed on molten surface at harsher irradiation conditions, e.g. $2460{ }^{\circ} \mathrm{C}$ and $2.3 \times 10^{22} \mathrm{He} / \mathrm{m}^{2}$, and they are replaced by porous or coral-like structures which are still grain dependent. Tokunaga et al.'s work [10] reported that the blisters did not appear any longer when the peak temperature reached a relatively high level. Zenobia et al. [18] well showed the progression from blisters to grass structure with increasing helium fluence. Based on the observations in [18], it is reasonable to conjecture that: there might be some blisters formed at M3, and when the temperature and helium fluence increased these blisters ruptured and the lids were removed, and furthermore, the pores left on the damaged surface as shown in Fig. 5(d) continued to evolve and resulted in the porous or coral-like structures (Fig. 6(b)). It is pity that the grain orientation cannot be detected by EBSD at M3 due to the serious surface damage, and therefore, the evolution of surface morphology for different grain orientations with increasing temperature and helium fluence is not clear at present. To elucidate the exact mechanism of helium-induced surface modifications varying with grain orientations, further study using single crystal W samples with different orientations and more detailed structural analysis (e.g. transmission electron microscopy (TEM)) is required. 
On the circumjacent non-molten surface, no blisters are formed under the similar helium irradiations in step II (Fig.4). It is supposed to be closely related to the resulting surface structure after step I. Different from the uninjured smooth resolidified grains (with fewer defects), the non-molten surface has been damaged with a depth of $\sim 1 \mu \mathrm{m}$ after the pre-irradiation in step I, where a lot of bubbles and holes have been already generated (Fig. 3(d)) which could act as the paths for the helium bubbles to connect with each other resulting in even worse porous structure (Fig. 4).

Besides the surface features, the depth of damaged surface is also an important concern. The experimental results show that damaged surface depth increases significantly with increasing surface temperature and local helium fluence for both molten and non-molten W surface. By examining the FIB cross-sectional images, enhanced helium bubble formation and growth is the key contributor. The helium bubble formation is sometimes ascribed to the strong attractive interaction between helium atoms and vacancies/vacancy clusters [19]. When the temperature increases, the thermal migration of vacancies and bubble coalescence get more intense, and result in more bubble formation and the growth of the individual bubbles [2]. In our experiments, the local helium fluence is simultaneously increased. It has been reported that increasing helium fluence could enhance the coalescence and growth of helium bubbles [20]. Compared with the extent of surface damage between the molten positions and non-molten positions under analogy irradation conditions (N2 $(\sim 0.3 \mu \mathrm{m})$ and M1 $(\sim 0.2 \mu \mathrm{m}), \mathrm{N} 4(\sim 1.2 \mu \mathrm{m})$ and M3 $(\sim 0.9 \mu \mathrm{m}))$, the molten positions suffer less 
damage. The pre-irradiation effect in step I should be certainly taken into account for this comparison. For molten surface, there is little pre-irradiation effect in molten area which can be verified by the smooth surface in Fig. 3(b) and the intact bulk in Fig. 5(d). However, the pre-irradiation damage is significant in non-molten area as shown in Fig. 3(d), which can accelerate the surface damage during step II as we have discussed above. In this work, the molten and non-molten areas locate on one big W sample. So the pre-irradiation effect on the non-molten surface cannot be eliminated. Using individual undamaged $\mathrm{W}$ to repeat this comparison is planned as our future work.

\section{Conclusions}

Surface modifications of the molten and non-molten $\mathrm{W}$ under the synergistic HHF loading and helium irradiation have been comparatively investigated with high heat flux helium neutral beam pulses in GLADIS. Surface morphology changes are observed after helium irradiation with an accumulated fluence of $1.2-2.5 \times 10^{22} \mathrm{He} / \mathrm{m}^{2}$ at the peak temperatures from $1450{ }^{\circ} \mathrm{C}$ to $2590{ }^{\circ} \mathrm{C}$. The experimental results indicate that helium-induced surface modifications of the molten and non-molten surface are very different. Surface morphology of non-molten surface changes from porous structure with a large number of pinholes to coral-like structure with increasing surface temperature and local helium fluence. On the molten surface, blistering is observed and its degree highly depends on the grain orientation: resolidified grains near (001) surface orientation are least affected and the ones near (011) are medium, 
and the ones near (111) suffer greatest damage. However, when the peak temperature and local helium fluence rise to $2460{ }^{\circ} \mathrm{C}$ and $2.3 \times 10^{22} / \mathrm{m}^{2}$, blisters cannot be found and the surface morphology evolve into porous or coral-like structure which also depends on the grains. The depth of surface damage for both of molten and non-molten surface significantly increases with increasing peak temperature and helium fluence.

\section{Acknowledgements}

This work was supported by National Magnetic Confinement Fusion Science Program of China under Grant 2013GB109004, the National Nature Science Foundation of China under contract nos. 51071095 and 50971077, and the Joint Sino-German research project GZ 763 .

\section{References}

[1] A. Loarte et al., Nucl. Fusion, 47 (2007) S203.

[2] N. Yoshida, H. Iwakiri, K. Tokunaga and T. Baba, J. Nucl. Mater. 337-339 (2005) 946.

[3] M. Miyamoto, D. Nishijima, Y. Ueda, et al., Nucl. Fusion 49 (2009) 065035.

[4] Y. Yuan, H. Greuner, B. Böswirth, et al., J. Nucl. Mater., 2012, accepted.

[5] J.W. Coenen, V. Philipps, S. Brezinsek, et al., Nucl. Fusion 51 (2011) 113020. 
[6] H.Greuner, et al., Fusion Eng. Des. 82 (2007) 1713.

[7] H.Greuner, et al., Fusion Eng. Des. 75-79 (2005) 345.

[8] Y. Yuan et al., Recrystallization and grain growth behavior of rolled tungsten under VDE-like short pulse high heat flux loads, J. Nucl. Mater., 2012, in press.

[9] H. Greuner et al., J. Nucl. Mater. 417 (2011) 495.

[10] K. Tokunaga, S. Tamura, N. Yoshida, et al., J. Nucl. Mater., 329-333 (2004) 757.

[11] D. Nishijima, M.Y. Ye, N. Ohno and S. Takamura, J. Nucl. Mater. 313-316 (2003) 97.

[12] D. Nishijima, M.Y. Ye, N. Ohno and S. Takamura, J. Nucl. Mater. 329-333 (2004) 1029.

[13] R. Behrisch, W. Eckstein (Eds.), Sputtering by Particle Bombardment, Springer, Berlin, 2007.

[14] S. Kajita, W. Sakaguchi, N. Ohno, et al., Nucl. Fusion 49 (2009) 095005.

[15] W.M. Shu, A. Kawasuso, Y. Miwa, E. Wakai, G.-N. Luo and T. Yamanishi, Phys. Scr. T128 (2007) 96.

[16] J.H. Evans, J. Nucl. Mater. 68 (1977) 129.

[17] J.H. Evans, J. Nucl. Mater. 76 \& 77 (1978) 228.

[18] S.J. Zenobia, L.M. Garrison, G.L. Kulcinski, J. Nucl. Mater. 425 (2012) 83.

[19] C.C. Fu and F. Willaime, Phys. Rev. B 72 (2005) 064117.

[20] B.B. Cipiti, G.L. Kulcinski, J. Nucl. Mater. 347 (2005) 298. 
Table 1. The main loading parameters for the nine investigated positions on the sample W1.

Fig. 1. (a) Two pieces of $\mathrm{W}$ samples (W1 and W2) fixed on CFC sample holders. Positions P1 and P2 are the centre of the samples W1 and W2, respectively. (b) An image of the sample $\mathrm{W} 1$ exposed to the $10.5 \mathrm{MW} / \mathrm{m}^{2}$ loading for $4.6 \mathrm{~s}$ with the beam centre located at P1 (Step I).

Fig. 2. Profile of the Gaussian beam measured at the target position for a heat flux with central density of $10.5 \mathrm{MW} / \mathrm{m}^{2}$. The hatched areas indicate the power densities load on the sample W1 during step I and step II, respectively.

Fig. 3. SEM images of (a) the original grinding surface, (b) virgin resolidified surface in the centre and (c) porous structure of the non-molten area (N2) irradiated with helium fluence of $9.2 \times 10^{21} / \mathrm{m}^{2}$ at temperatures below the melting point in step I. (d) FIB cross-section of the non-molten area shown in (c).

Fig. 4. SEM images of the four positions (N1-N4) on the non-molten tungsten surface subsequently irradiated by five helium pulses in step II. The peak surface temperatures and helium fluences are (a) $1450{ }^{\circ} \mathrm{C}, 1.2 \times 10^{22} / \mathrm{m}^{2}$, (b) $1800{ }^{\circ} \mathrm{C}$, $1.6 \times 10^{22} / \mathrm{m}^{2}$, (d) $2340{ }^{\circ} \mathrm{C}, 2.2 \times 10^{22} / \mathrm{m}^{2}$, (e) $2590{ }^{\circ} \mathrm{C}, 2.5 \times 10^{22} / \mathrm{m}^{2}$. (c) and (f) are cross-sectional images correspond to (b) and (e), respectively.

Fig. 5. (a) Surface morphology of the molten tungsten surface irradiated with repeated helium pulses at the peak temperature of $1730{ }^{\circ} \mathrm{C}$ and helium fluence of $1.4 \times 10^{22} / \mathrm{m}^{2}$ (M1). (b) Magnification of (a). (c) Inverse pole figure of the normal direction (ND) of the grain surface with respect to the cubic axes of the grains. The degree of blistering 
on the grains is classified to "light", "medium" and "heavy" which indicated by different symbols. (d) FIB cross-section corresponds to the location indicated by the red line in (b).

Fig. 6 (a) Surface morphology of molten position $\mathrm{M} 2\left(1950{ }^{\circ} \mathrm{C}, 1.8 \times 10^{22} / \mathrm{m}^{2}\right)$. (b) Surface morphology of molten position M3 $\left(2460{ }^{\circ} \mathrm{C}, 2.3 \times 10^{22} / \mathrm{m}^{2}\right)$. (c) and (d) Cross-sections of grain F and G shown in (b), respectively. 
Table 1.

\begin{tabular}{|c|c|c|c|c|c|c|c|}
\hline Position & N1 & $\mathrm{N} 2$ & $\mathrm{~N} 3$ & $\mathrm{~N} 4$ & M1 & M2 & M3 \\
\hline \multirow{3}{*}{ Step I } & \multicolumn{4}{|c|}{ Fluence: $9.2 \times 10^{21} / \mathrm{m}^{2}$} & \multicolumn{3}{|c|}{ Time: $4.6 \mathrm{~s}$} \\
\hline & \multicolumn{7}{|c|}{ Peak temperature $\left({ }^{\circ} \mathrm{C}\right)$} \\
\hline & \multicolumn{4}{|c|}{3100 -up to 3410 (non-molten) } & \multicolumn{3}{|c|}{$>3410$ (molten) } \\
\hline \multirow{5}{*}{ Step II } & \multicolumn{7}{|c|}{ Time: $3 \cdot 5+3.7+3.9+4.1+4.3 \mathrm{~s}$} \\
\hline & \multicolumn{7}{|c|}{ Fluence $\left(\times 10^{22} / \mathrm{m}^{2}\right)$} \\
\hline & 1.2 & 1.6 & 2.2 & 2.5 & 1.4 & 1.8 & 2.3 \\
\hline & \multicolumn{7}{|c|}{ Peak temperature $\left({ }^{\circ} \mathrm{C}\right)$} \\
\hline & 1450 & 1800 & 2340 & 2590 & 1730 & 1950 & 2460 \\
\hline
\end{tabular}


Fig. 1
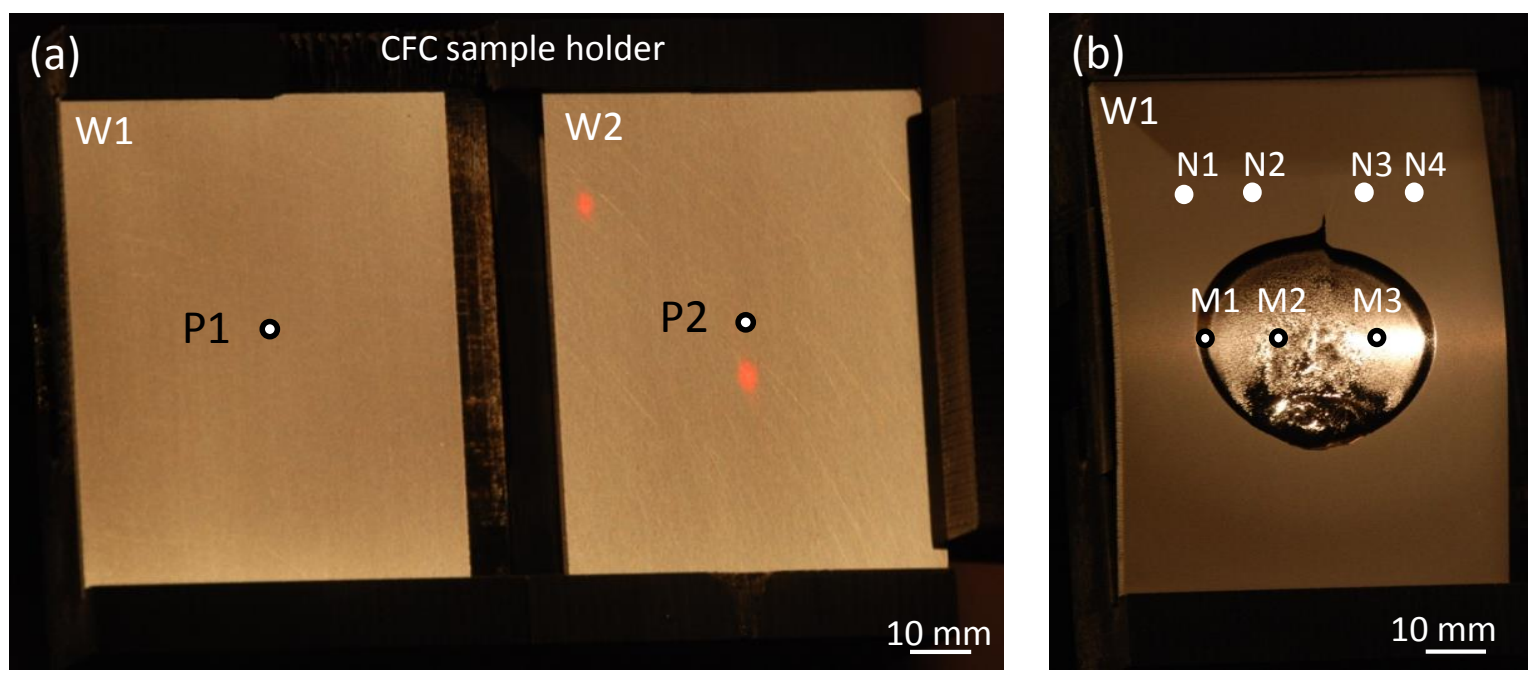
Fig. 2

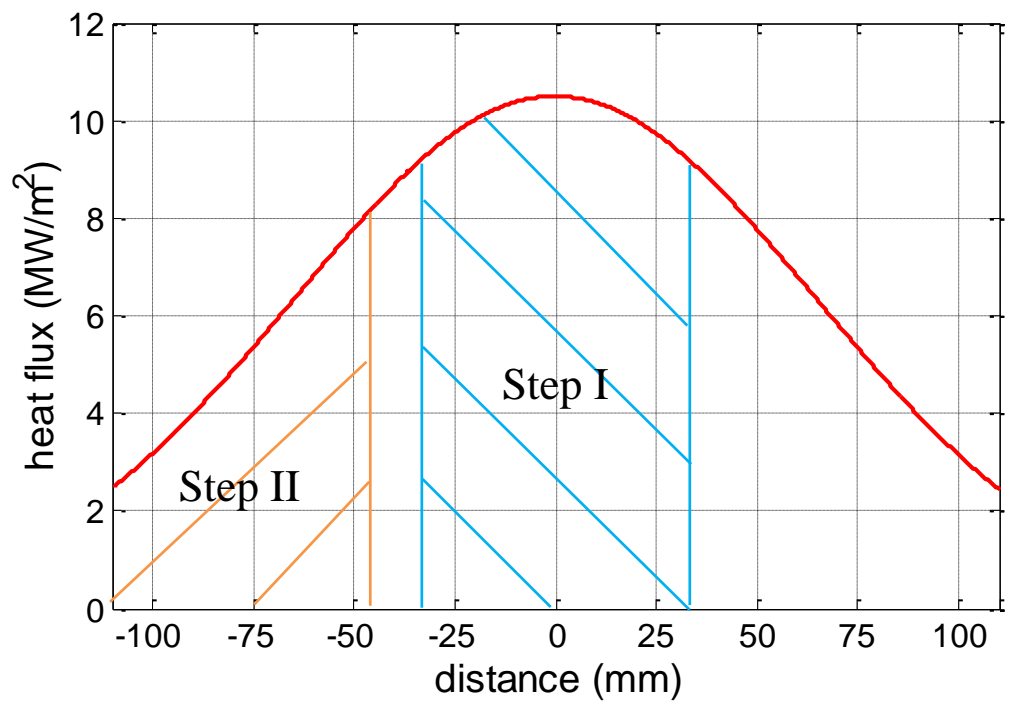


Fig. 3
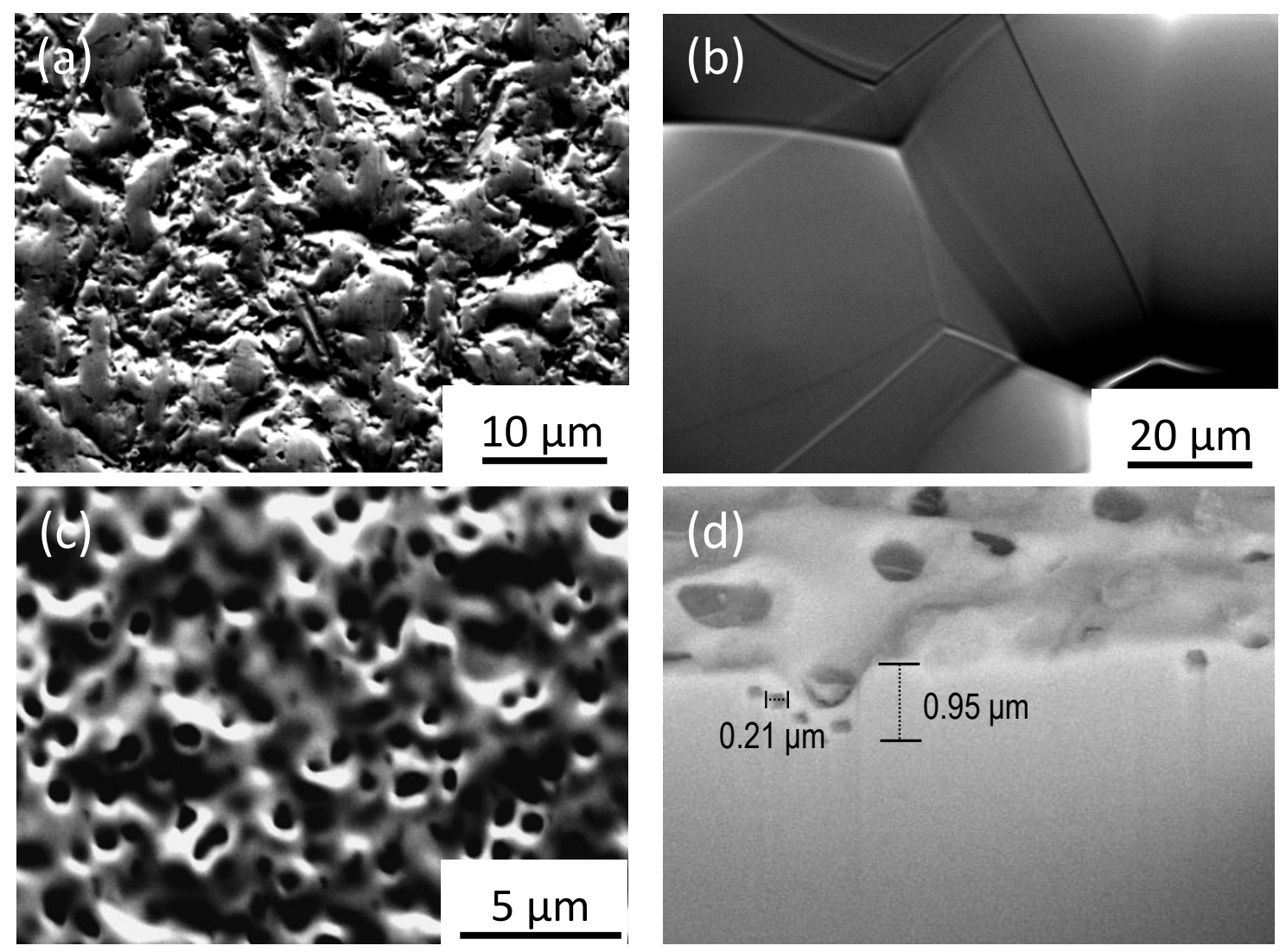
Fig. 4
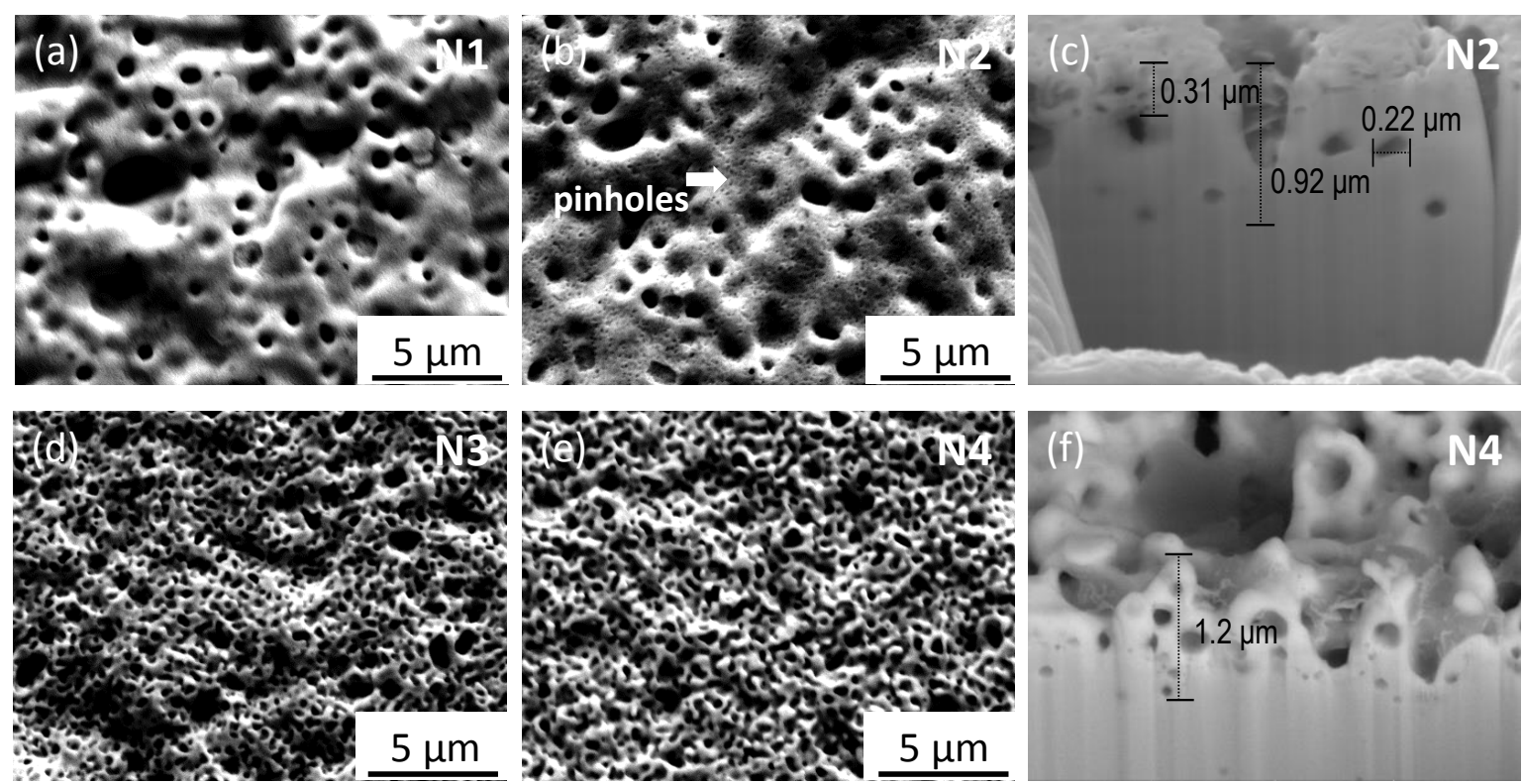
Fig. 5

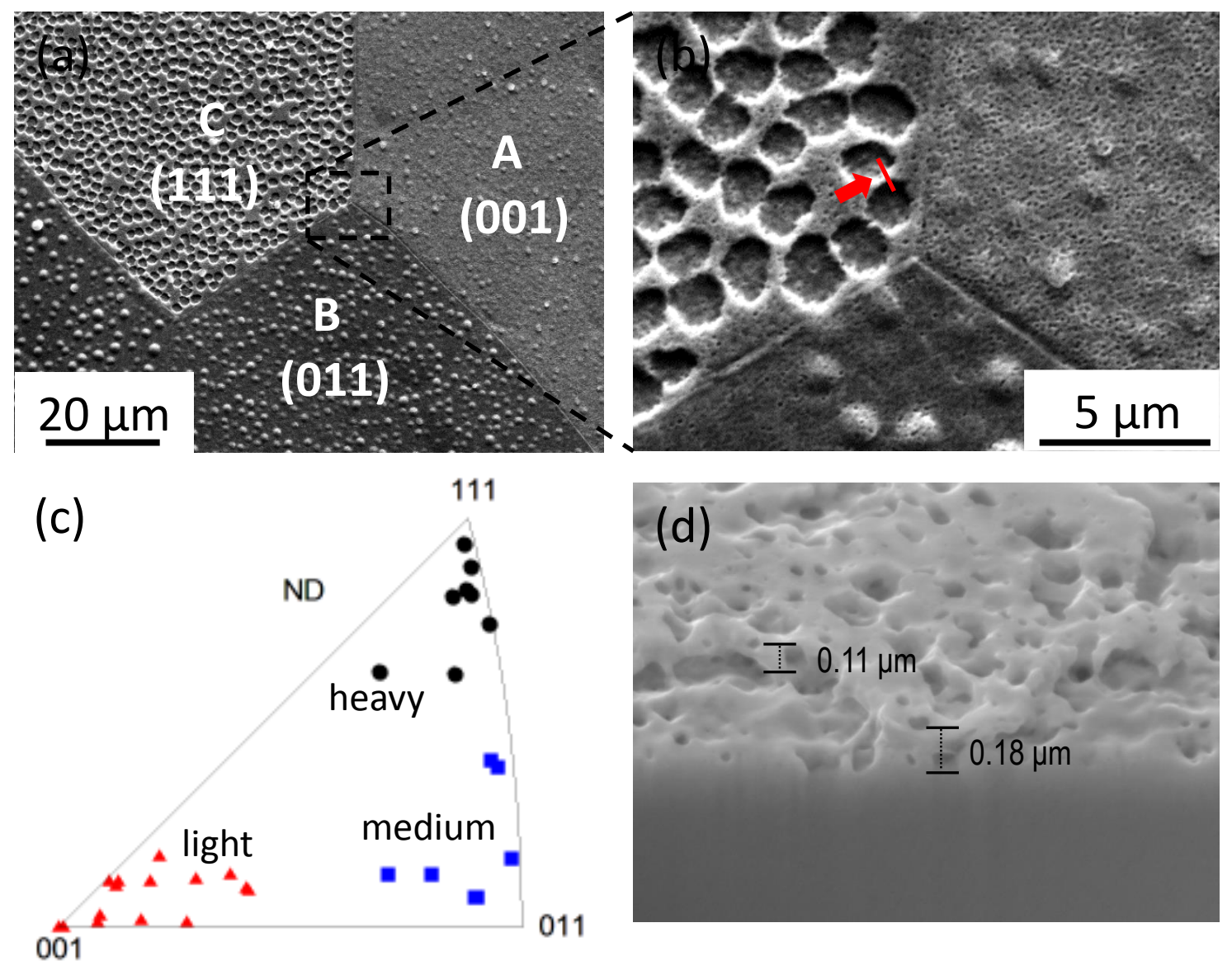


Fig. 6
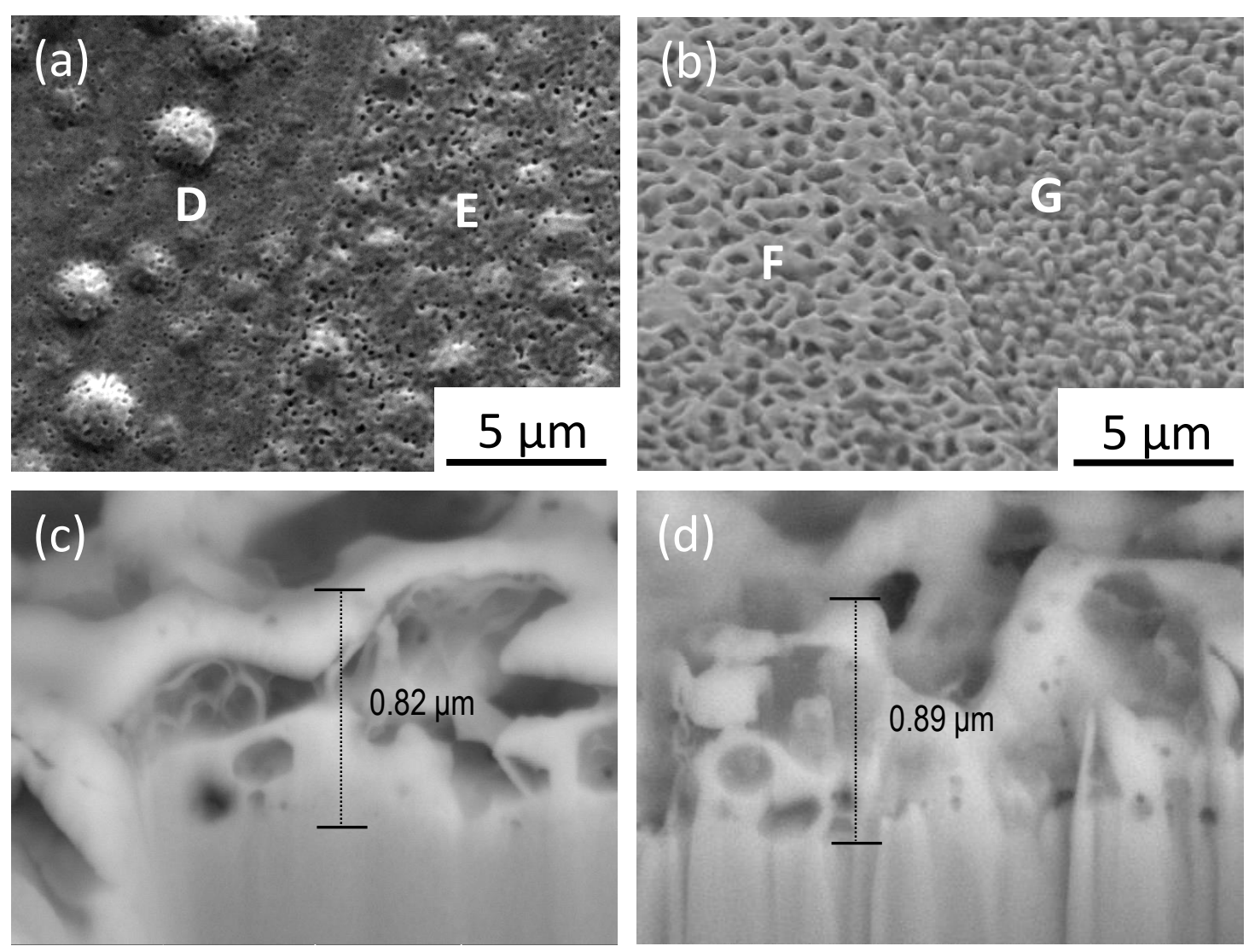